\title{
Risk Management Methods in Projects
}

\author{
Petr Rehacek and Blanka Bazsova \\ VŠB-Technical University of Ostrava, Faculty of Economics, Ostrava, Czech Republic \\ Correspondence should be addressed to: Petr Rehacek; perehacek@gmail.com \\ Received date: 2 October 2017; Accepted date: 27 November 2017; Published date: 22 May 2018 \\ Academic Editor: Lucian-Ionel Cioca \\ Copyright (C) 2018. Petr Rehacek and Blanka Bazsova. Distributed under Creative Commons \\ CC-BY 4.0
}

\begin{abstract}
The risks cause cost and time overruns in all types of projects and the risk management methods should be implemented in all types of projects. The paper presents risk assessment methods which aim to identify, analyze and evaluate the risks associated with the projects. Especially construction objects life cycle is full of various risks. Risks come from many sources: temporary project team that is collected from different companies, construction site, changes in customer preferences, etc. Moreover, the size and complexity of reality and surrounding are increasing which adds to the risks. The object risks can be identified and evaluated by using the Pareto analysis, Saaty's matrix or decision tree. We can assess uncertain events or conditions which have a positive or negative effect on at least one construction project objective.
\end{abstract}

Keywords: evaluation, management, methods, project, risk

\section{Introduction}

The risk factor in construction business is very high. Construction objects are unique and built mostly only once. Risk management is a concept which is used in all industries, from IT related business, automobile or pharmaceutical industry, to the construction sector. Each industry has developed their own risk management standards, but the general ideas of the concept usually remain the same regardless of the sector. Decision- making is very important in the management of projects, such as risk assessment results in huge and important projects, contractor and supplier selection, etc. Each project manager should have a basic knowledge about risks associated to a project and how to handle them. Risk management should be conducted on all projects. The degree, level of detail, sophistication of tools, and amount of time and resources applied to risk management should be in proportion to the characteristics of the project under management and the

Cite this Article as: Petr Rehacek and Blanka Bazsova (2018)," Risk Management Methods in Projects ", Journal of Eastern Europe Research in Business and Economics, Vol. 2018 (2018), Article ID 790198, 
value that they can add to the outcome. Thus, a large project that provides value to an important customer would theoretically require more resources, time, and attention to risk management than would a smaller, short-term, internal project that can be conducted in the background with a flexible deadline.

The principles of risk management should be appropriately applied based on the specifics of a project and the organizational environment. Risk management provides benefits when it is implemented according to good practice principles and with organizational commitment to taking the decisions and performing actions in an open and unbiased manner.

The risk management process is extreme and important. Risk measure includes risk level determination of each objective and the risk analysis estimation by applying various approaches and technology. Risk control process evaluates performance of risk control. Risk identification is the first and main step of risk management process. It is describing the competitiveness conditions and the clarification of risk and uncertainty factors (Rutkauskas, 2008; Zayed et al., 2008), recognition of potential sources of risk and uncertainty event responsibilities. According to Zavadskas et al. (2008), the project risks can be divided into three groups - external risks, project risks and internal risks. External risks are those risks that are beyond the control of the project management team. Internal risks can be divided according to the party who might be the originator of risk events such as stakeholders, designer, contractor, etc. There are various classification ways of risk management methods. External risks (environmental criteria) involve political risk, economic risk, social risk and weather risk.

Political risks are changes in government laws of legislative system, regulations and policy and improper administration system, etc. (Li and Liao, 2007).
Economic risks. There is inconstancy of economy in the country, repayment situation in manufacture sphere, inflation and funding. Considering the current economic situation, this result can be reasonably expected (Tvaronavičienè and Grybaitè, 2007).

Social risks are the growing importance to any effort at risk allocation. It is an area in which political and social pressures from parties having little interest in a project but having a great impact on such a project greatly influence its outcome. The impact of the financial aid on the social and economic development of the region is analyzed by Ginevičius and Podvezko (2009), risk communication in organizations is analyzed by Conchie and Burns (2008).

Weather risk. Except for extremely abnormal conditions, it is a risk for the contractor to assume, as its impact on construction methods can be assessed by the contractor.

Project risks methodology is described in PMI book and IPMA Competence Baseline Rehacek (2017b). The specific criteria such as recognizing the value of Risk Management, individual commitment (responsibility), open and honest communication, organizational commitment, risk effort scaled to project and integration with Project Management are included in each risk management process (PMI, 2013). The relationship between project risks and IT brought many authors (Ropponen and Lyytinen 1997, 2000; Yetton et al. 2000; Kwak and Stoddard 2004; Na et al. 2004; Zwikael and Globerson 2006; Han et al. 2007; Jiang et al. 2009). Many studies pointed out the hard side of the impact of the risk management on the project success. Monteiro de Carvalho and Rabechini Jr. Brought examined the impact of risk management on project performance. They pointed out the importance of soft skills. The main groups of criteria of the construction projects risks belong to: 
1. Time risk

2. Cost risk

3. Work quality

4. Construction risk

5. Technological risk

Time risk can be determined by appraisal of the delay at construction, technology and for all works.

Cost risk. The cost of opportunity product grows due to neglecting management (Zavadskas et al., 2008).

Risk evaluation $=\left(\begin{array}{ccccc}1 & 1 & 3 & 5 & 7 \\ 1 & 1 & 3 & 3 & 5 \\ 1 / 3 & 1 / 3 & 1 & 3 & 3 \\ 1 / 5 & 1 / 3 & 1 / 3 & 1 & 3 \\ 1 / 7 & 1 / 5 & 1 / 3 & 1 / 3 & 1\end{array}\right)$

If we use Saaty's matrix to assess the importance of these risks, we can achieve the results shown in Table 1 . According to the expert 's assessment we can calculate the
Work quality. Deflective work is considered a significant risk factor in this category because not only does it result in construction delays and additional cost to the contractor but it easily leads to disputes on the liability for the deflection.

Construction risk. The risks are involved in construction delay, changes in the work and construction technology.

Technological risk. Designing errors, lack of technologies, management errors, shortage of the qualified labour.

Table 1: Types of risk evaluated by using Saaty's matrix (own calculation)

\begin{tabular}{|l|c|c|}
\hline & Geomean & Weight \\
\hline Time risk & 2.5365 & 0.386 \\
\hline Cost risk of & 2.1411 & 0.326 \\
\hline $\begin{array}{l}\text { Work quality } \\
\text { qunstruction } \\
\text { risk }\end{array}$ & 0.5818 & 0.152 \\
\hline $\begin{array}{l}\text { Technological } \\
\text { risk }\end{array}$ & 0.3165 & 0.048 \\
\hline
\end{tabular}

Pareto analysis is based on the principle that $80-95 \%$ of the problems are caused by a small number of causes of $5-20 \%$. These causes were formulated by Pareto; he described them as a vital minority. For these reasons, it is necessary to focus, analyze them in depth and eliminate them to minimize their impact. The other causes were later named by Juran to a useful majority. It is based on the $80 / 20$ rule, which means that $80 \%$ of the problems are caused by $20 \%$ of the causes. We have to create a

Petr Rehacek and Blanka Bazsova (2018), Journal of Eastern Europe Research in Business and Economics, DOI:10.5171/2018.790198 
cumulative number of deficiencies and a cumulative number of deficiencies in percentage. Diagram is made of two charts histogram and Lorenz curve. A graphical representation of Pareto's claim, sometimes called the 80/20 rule, is Pareto diagram. Pareto diagram is a diagram that helps to analyze causes that cause a problem. From the Pareto diagram it is possible to determine vital causes, respectively factors that need to focus on solving the problem. This diagram is composed of a bar graph and a Lorenz curve. The column graph is a cumulative number, Lorenz curve of relative frequency. To determine vital factors is a significant factor of the average factor (50\%) that can be found on the Lorenz curve. Those factors above the average are a vital minority. (Bazsova, 2014).

A survey provided in 2016 with the managers of the SME showed the biggest frequency of the risk at the adverse weather.

9.
The authors made the similar survey in 2017. The information provided Attn Consulting Company. The survey revealed the main risks parameters, which are connected with the projects. The results are displayed on table 2 and figure 1, which have shown that most companies rated the severity of the 5 most serious types of risk.

The most serious risks in a project-based organization include:

1. Risk of non-compliance with delivery date

2. Risk of non-compliance with workflows

3. Risk of unforeseen costs

4. Risk of non-payment of invoices by customers

5. The risk of adverse weather

6. Risk of current and ex-employees

7. Risk of hackers

8. Risk of competitors

Table 2: The most serious types of risks from the survey

\begin{tabular}{|l|r|}
\hline Type of risk & Frequency \\
\hline Risk of non-compliance with delivery date & 200 \\
\hline Risk of non-compliance with workflows & 186 \\
\hline Risk of unforeseen costs & 159 \\
\hline Risk of non-payment of invoices by costumers & 148 \\
\hline Risk of the adverse weather & 108 \\
\hline Risk of competitors & 49 \\
\hline Risk of hackers & 11 \\
\hline Risk of current-and ex-employees & 2 \\
\hline Total number of cases & 863 \\
\hline Average & 107.875 \\
\hline Median & 128 \\
\hline Std. Deviation & 73.2076456 \\
\hline
\end{tabular}

Petr Rehacek and Blanka Bazsova (2018), Journal of Eastern Europe Research in Business and Economics, DOI:10.5171/2018.790198 


\section{Type of risk in projects}

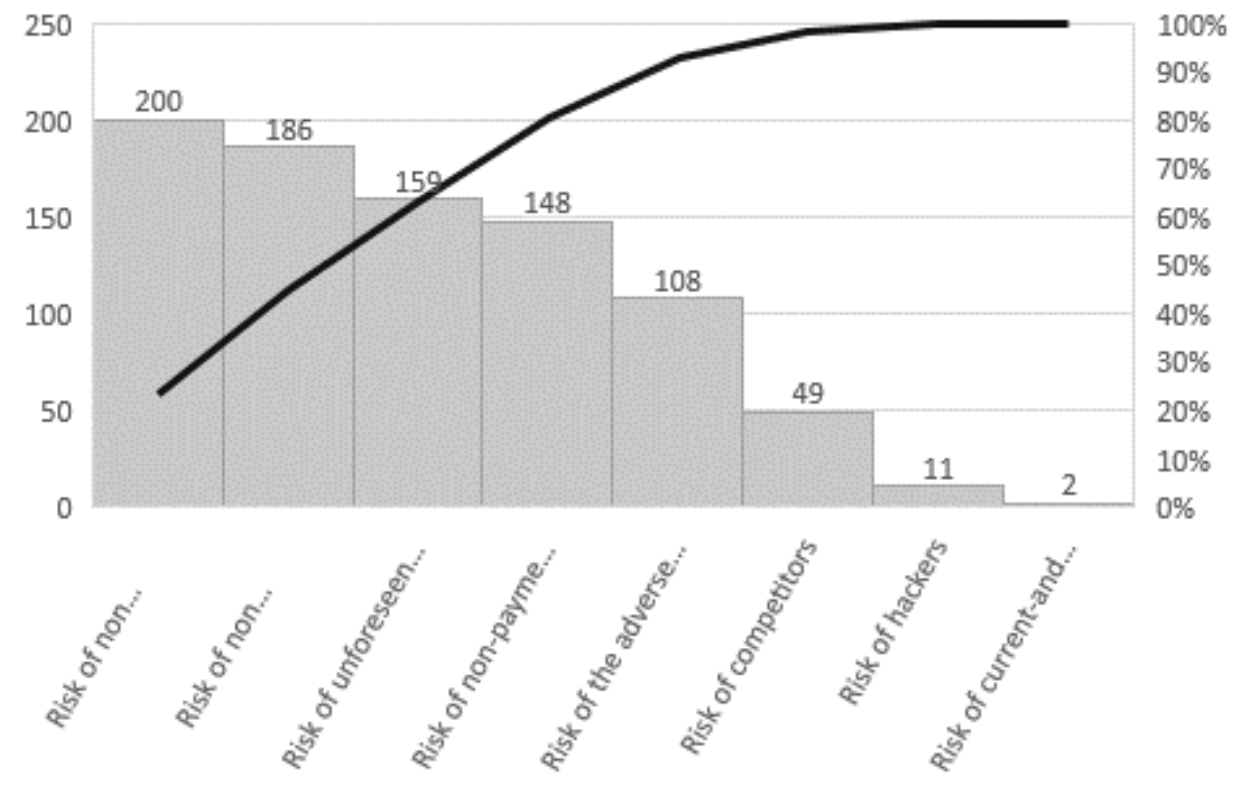

Fig. 1: Pareto diagram (own calculation)

Pareto diagram showed that the importance is at the first 3 types of risk: the risk of non compliance with the delivery date, the risk of non compliance with workflows and the risk of unforeseen costs. (see Fig. 2)

\section{Internal (Intrinsic) Risks:}

- Resource risk

- Project member risk

$\begin{array}{cl}\circ & \text { Stakeholders' risks } \\ \circ & \text { Designers risk } \\ \circ & \text { Contractor risk } \\ \circ & \text { Subcontractor risk } \\ \circ & \text { Suppliers risk } \\ \circ & \text { Team risk }\end{array}$

- Construction site risk

- Documents and information risk

Resource risk. Materials and equipment involve considerable risks. The availability and productivity of the resources necessary to construct the project are risks which are proper for the contractor to assume (Fisk, 2003).

Project member risk. Team risk refers to issues associated with the project team members, which can increase the uncertainty of a project's outcome, such as team member turnover, staffing build up, insufficient knowledge among team members, cooperation, motivation, and team communication issues.

Stakeholders' risks rightfully belong to the stakeholder alone and should be retained by stakeholders except to the extent that they are influenced by construction methods determined by the contractor, or created by suppliers controlled by the contractor. Stakeholders' influence on the external environment is analyzed by Mitkus and Sostak (2008).

Designers risk. The expansion of construction has placed great burdens upon the design professions. Maintaining performance standards in the face of this is

Petr Rehacek and Blanka Bazsova (2018), Journal of Eastern Europe Research in Business and Economics, DOI:10.5171/2018.790198 
quite difficult, and occasionally, design or specification deflections occur that create construction problems. Design failures or constructability errors are becoming more and more apparent, and the architect should bear the true cost of such failures.

Contractor risk. The prime or general contractors are in the best position to assess the capacity of their subcontractors, and therefore it is they who should bear the risk of not assessing the risk properly.

Subcontractor risk is properly assumed by the contractor except where it arises from one of the other listed risks attributable to stakeholder or architect (Fisk, 2003).

Suppliers risk. Default from obligations of the supplier (Fisk, 2003).

Team risk. Team risk refers to issues associated with the project team members that can increase the uncertainty of a project's outcome, such as team member turnover, staffing build up, insufficient knowledge among team members, cooperation, motivation, and team communication issues. The working team must analyze the business activities of all alliance members and identify various risk factors in business activities and their characters (Gunstone, 2003; Li and Liao, 2007; Li et al., 2007).

Construction site risk. Accident exposures in workplace are inherent in the nature of the work and are best assessed by the contractors and their insurance and safety advisors (Fisk, 2003).

Documents and information risk. It assumes: contradiction in documents; pretermission; law and communication.
Changed order negotiation and delayed dispute resolution are significant risks during project construction. Communication is very important at all construction period and after finishing construction work.

Likewise, risk management has become a timely issue widely discussed across industries. There has been study conducted by Rehacek (2017a) in three countries which emphasizes the importance of the project context considering the industry. However, with regard to the construction industry, risk management is not commonly used. More construction companies are starting to become aware of the risk management process, but are still not using models and techniques aimed for managing risks. This contradicts the fact that the industry is trying to be more cost and time efficient as well as have more control over projects. The construction industry operates in a very uncertain environment where conditions can change due to the complexity of each project (Sanvido et al., 1992). The aim of each organization is to be successful and risk management can facilitate it. However, it should be underlined that risk management is not a tool which ensures success but rather a tool which helps to increase the probability of achieving success. Risk management is therefore a proactive rather than a reactive concept (Tsai and Yong, 2010). They point out naturel phenomena like earthquake, fire, high gale, rainfall; economics phenomena like materials' costs, difficulty of financing, low market demand, exchange rate fluctuation, politics phenomenon like change of laws, bribery, corruption, etc.

This study brought results from the Czech Republic construction companies. They have been addressed. 


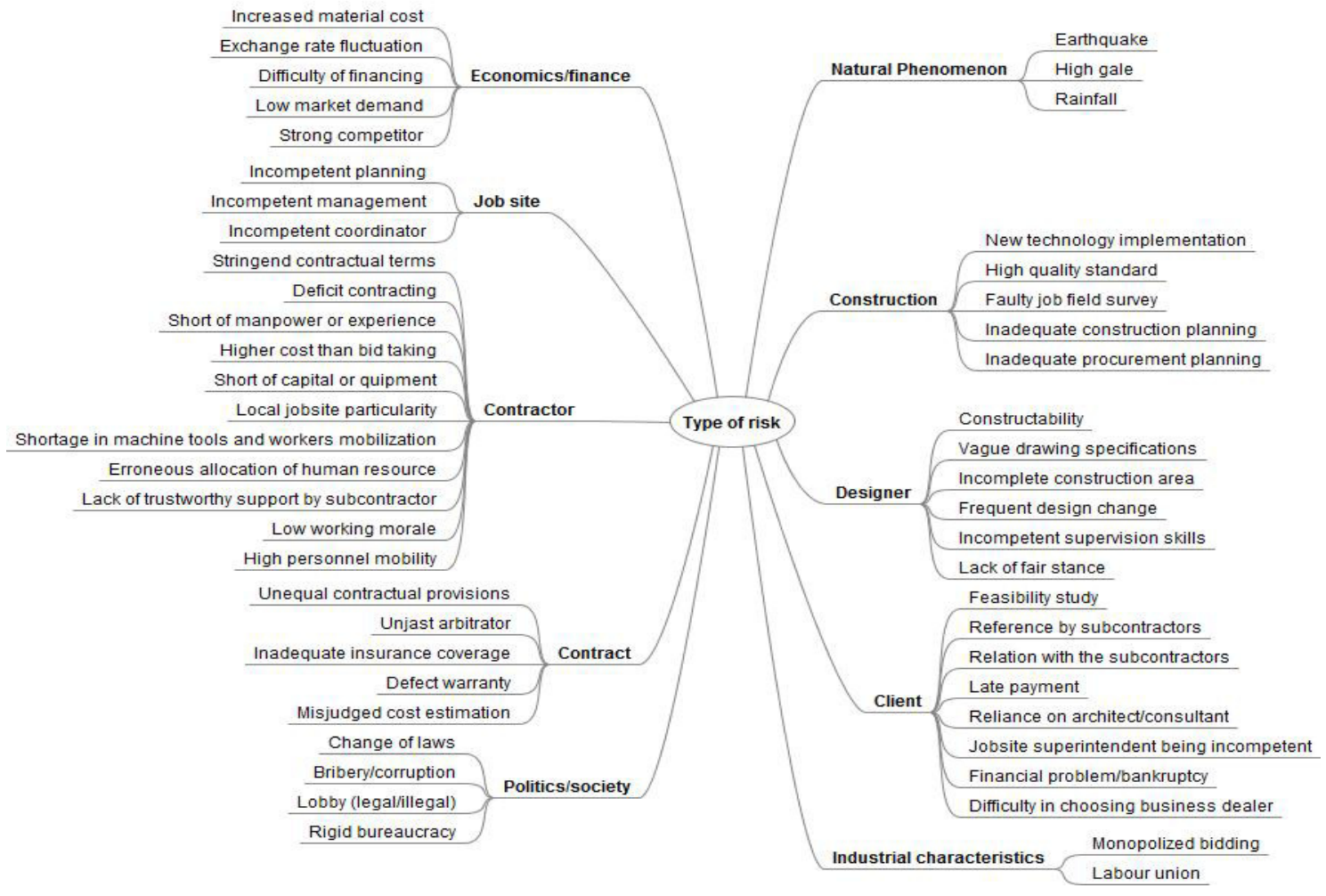

Fig. 2: Project risk structure tree (redesigned by Tsai and Yang, 2010)

Risk Response Planning can be done by the following methods (Rajendhran and Sundar, 2011; Rehacek, 2016):

1. Risk Avoidance: Risk can be warded off by removing the cause of the risk of executing the project in a different direction while still aiming to accomplish project objectives. Change project management plan to eliminate a threat, to isolate project objectives from the risk's impact, or to relax the project objective that is in jeopardy, such as extending schedule or reducing the scope.

2. Risk Transfer: Transferring risk involves finding some other party who is willing to accept responsibility for its management, and who will bear the liability of the risk should it occur. Transferring a threat does not eliminate it; the threat still exists however it is owned and managed by another party. Transferring risk can be an effective way to deal with financial risk exposure. The aim is to ensure that the risk is owned and managed by the party best able to deal with it effectively.

3. Risk Mitigation / Reduction: Risk mitigation reduces the probability and/or impact of an adverse risk event to an acceptable threshold. Taking early action to reduce the probability and/or impact of a risk is often more effective.

4. Risk Exploit: This strategy seeks to eliminate the uncertainty associated with a particular upside risk by creating the opportunity. Eliminate

Petr Rehacek and Blanka Bazsova (2018), Journal of Eastern Europe Research in Business and Economics, DOI:10.5171/2018.790198 
the uncertainty associated with a particular upside risk. An opportunity is defined as a risk event that if it occurs it will have a positive effect on achievement of project objectives.

5. Risk Share: Allocate risk ownership of an opportunity to another party who is best able to maximize its probability of occurrence and increase the potential benefits if they happen. Transferring threats and sharing opportunities are similar in that a third party is used, those to whom the threats are transferred take on the liability and those to whom opportunities are allocated should also be allowed to share in the potential benefits.

6. Risk Enhance: This response aims to alter the "size" of the positive risk. The opportunity is enhanced by increasing its probability and/or impact, thereby maximizing the benefits gained from the project. Seeking to facilitate or strengthen the cause of the opportunity, and proactively targeting and reinforcing its trigger conditions.

7. Risk Acceptance: Ultimately, it is not possible to eliminate all threats or take advantage of all opportunities we can document them and at least provide awareness that these exist and have been identified, some term this "passive acceptance”. This strategy is adopted when it is not possible or practical to respond to the risk by the other strategies, or a response is not justified by the grandness of the risk. When the project manager and the project team decide to accept a risk, they are agreeing to address the risk, if and when it happens. This involves the use of a fallback (contingency) plan if a risk occurs. Contingencies can also be in the form of sometime kept in reserve to deal with unknown risks or in the form of costs to deal with unknown risks.

8. Risk Control: is the final step of the process (Rajendhran and Sundar, 2011; Rehacek, 2016). After we have implemented response actions, we must track and record their effectiveness and any changes to the project risk profile. Did the response actions have a positive or negative effect on achieving project objectives? Responses taken in risks should also be documented for future reference and project plans.

\section{Risk Management Methods in Projects}

According to the Rajendhran and Sundar, 20011 and Rehacek, 2016 the Risk Identification can be done by brainstorming, Delphi Technigue, interview, past experience, checklist and questionnaire. Risk Assessment can be done by the following methods (according to Rajendhran and Sundar, 2011; Rehacek, 2016): Qualitative Method, where

$$
\begin{gathered}
\text { PI factor = Probability of Risk } \times \\
\text { Impact of Risk, }
\end{gathered}
$$

than Quantitative methods Sensitivity Analysis: This is carried out to identify the uncertainty and Scenario Analysis.

\section{Decision Trees}

The risk analysis is carried out by decision tree diagram. Decision trees are very helpful to both formulate the problem and evaluate options. In this analysis there are graphical models used to represent the project and can clearly reflect the effects of each decision taken in the project. The decision tree in figure 3 displays the evaluation of the project company, which has three possibilities of how to evolve under condition high, middle or low demand within four years. The

Petr Rehacek and Blanka Bazsova (2018), Journal of Eastern Europe Research in Business and Economics, DOI:10.5171/2018.790198 
company has 3 possibilities of its development in time: even fuse with other company or reduce its activities or stay in the same condition as in previous year (see fig. 3 ). The calculation has provided with the expectation of the high demand (probability 0.3 ) or with the middle demand (probability 0.5 ) or with the low demand (probability 0.2 ).

$$
\sum_{i, j=1}^{n} p_{i j}=1
$$

where: $i$ - expresses i-th node, $j$-expresses $\mathrm{j}$-th choice.

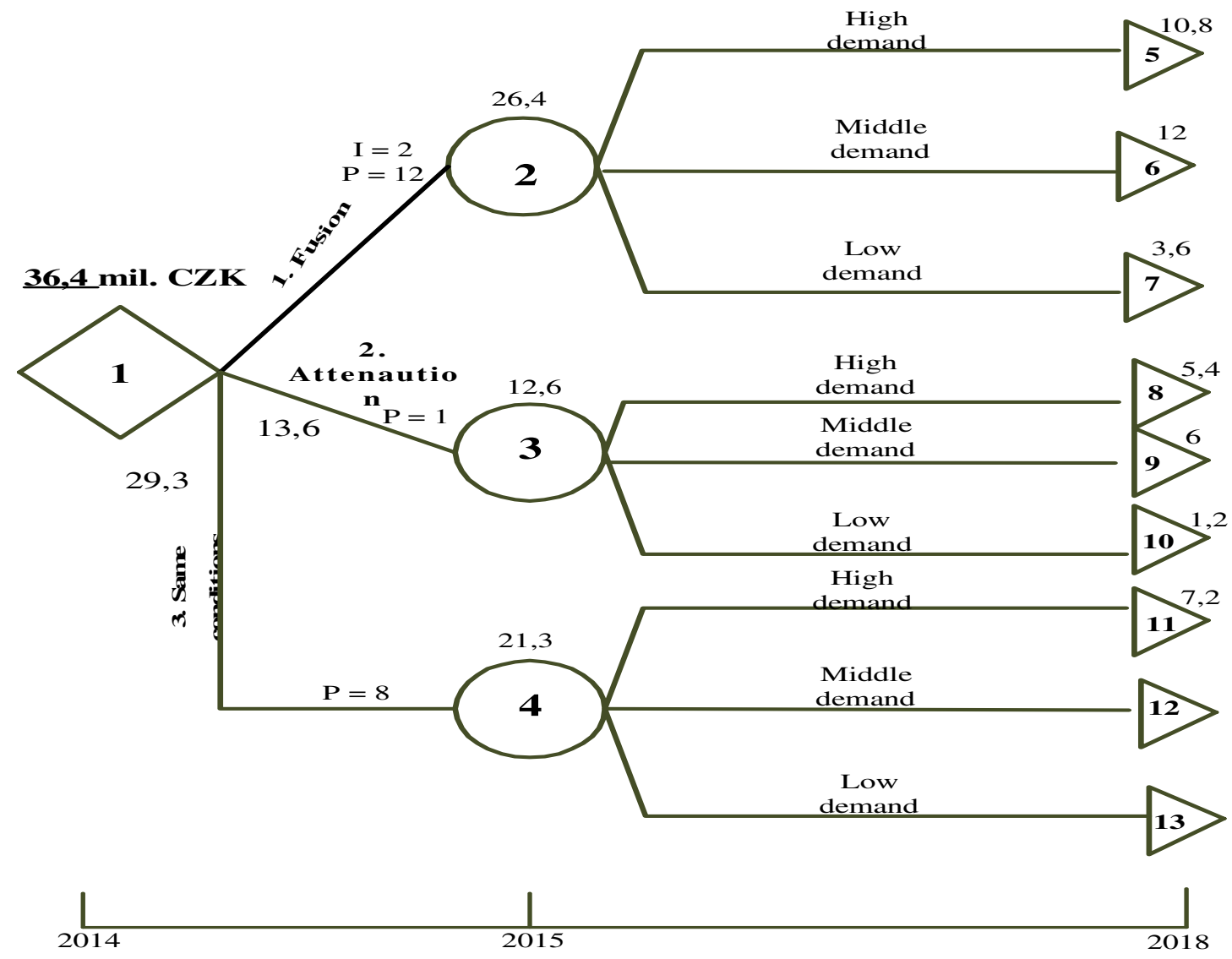

Fig. 3: Decision tree (own calculation)

Petr Rehacek and Blanka Bazsova (2018), Journal of Eastern Europe Research in Business and Economics, DOI:10.5171/2018.790198 


\section{Conclusions}

Risks are being managed every day in every industry, but not in such a structured way as the literature describes. However information provided in those sources is rather messy. Some theories provided by risk management literature are not at all applicable to specific industry. As also other researchers confirmed, the knowledge of risk management is close to zero, even though the concept of risk management is becoming more popular in the construction sector.

Professionals in the industry are using techniques described in the literature concerning risk management, but are not aware of it. Risk management technique is rarely used by the participants in projects. The participants used to handle the risks with an informal approach. This technique is not employed because of less knowledge and awareness among the industry. The risk management technique should be applied into any project at the initial stage of the project to get maximum benefit of the technique. Hence, there is a thriving need to have a well-documented procedure which should be a one item solution to all hazards that are likely to occur during project life cycle. There should be a more wholesome approach towards risk management instead of the present sporadic approach towards the risks.

\section{Acknowledgment}

This paper was supported within the Operational Programme for Competitiveness - Project No. CZ. 1.07/2.3.00/20.0296.

\section{References}

1. Bazsova, B. (2014), 'Analysis and Evaluation of Quality in University Education' Proceedings of the 24th International Business Information Management Association (IBIMA 2014), ISBN 978-09860419-3-8, 6-7 November 2014, Milan, Italy, 738-745.
2. Conchie, S. M.; Burns, C. (2008), 'Trust and risk communication in high-risk organizations: a test of principles from social risk research,' Risk Analysis 28(1), 141-149. doi:10.1111/j.1539-6924.2008.01006.x

3. Fisk, E. R. (2003). Construction Project Administration. Seventh Edition. Prentice Hall Upper Saddle River, New Jersey Columbus, Ohio.

4. Ginevičius, R.; Podvezko, V. (2009), 'Evaluating the changes in economic and social development of Lithuanian counties by multiple criteria methods,' Technological and Economic Development of Economy 15(3), 418-436. doi:10.3846/13928619.2009.15.418-436

5. Gunstone, S. (2003), 'Risk assessment and management of patients whom selfneglect: a 'grey area' for mental health workers,' Journal of Psychiatric and Mental Health Nursing 10(3), 287-296. doi:10.1046/j.1365-2850.2003.00568.x

6. Li, G.-D.; Yamaguchi, D.; Nagai, M. (2007), 'A grey-based decision-making approach to the supplier selection problem,' Mathematical and Computer Modelling, 46(3-4), 573-581. doi:10.1016/j.mcm.2006.11.021

7. Li, Y.; Liao, X. (2007), 'Decision support for risk analysis on dynamic alliance,' Decision Support Systems 42(4), 2043-2059. doi:10.1016/j.dss.2004.11.008

8. Mitkus, S.; Sostak, O. R. (2008), 'Modelling the process for defence of third party rights infringed while implementing construction investment projects,' Technological and Economic Development of Economy 14(2), 208-223. doi:10.3846/1392-

8619.2008.14.208-223

9. PMI. (2013). A Guide to the Project Management Body of Knowledge (PMBOK Guide). Fifth Edition. Project Management Institute Inc., USA.

Petr Rehacek and Blanka Bazsova (2018), Journal of Eastern Europe Research in Business and Economics, DOI:10.5171/2018.790198 
10. Rajendhran, N.; Sundar, P. (2011). A Study of Risk Assessment and Management in Construction. PSG College of Technology, Coimbatore, India.

11.Rehacek, P. (2016), 'Project Management Standards' Proceedings of the 27th IBIMA Conference on Innovation Management and Education Excellence Vision 2020: from Regional Development Sustainability to Global Economic Growth, ISBN 978-09860419-6-9, 4 - 5 May, 2016, Milan, Italy, 218-231. WOS:000381172300028

12.Rehacek, P (2017a), 'Risk management standards for project management,' International Journal of Advanced and Applied Sciences, $\quad 4(6)$, 1-13. doi:10.21833/ijaas.2017.06.001

13.Rehacek, P (2017b), 'Application and Usage of the Standards for Project Management and their Comparison,' Journal of Engineering and Applied Sciences, 12, 9941002. doi:10.3923/jeasci.2017.994.1002

14.Rutkauskas, A. V. (2008), 'On the sustainability of regional competitiveness development considering risk,' Technological and Economic Development of Economy 14(1), 89-99. doi:10.3846/2029-0187.2008.14.8999
15.Sanvido, V., Grobler, F., Parfitt, K., Guvenis, M., and Coyle, M. (1992), 'Critical Success Factors for Construction Projects,' Journal of Construction Engineering and Management, 118, (1), 94-111.

16.Tsai, T. C.; Yang, M. L. (2010), 'Risk Assessment of Design-Bid-Build and DesignBuild Building Projects,' Journal of the Operations Research Society of Japan, 53(1), $20-39$.

17.Tvaronavičienė, M.; Grybaitè, V. (2007), 'Impact of FDI on Lithuanian economy: insight into development of main economic activities,' Journal of Business Economics and Management 8(4), 285-290.

18.Zavadskas, E. K.; Turskis, Z.; Tamošaitiene, J. (2008), 'Contractor selection of construction in a competitive environment,' Journal of Business Economics and Management 9(3), 181-187. doi:10.3846/1611-1699.2008.9.181-187

19.Zayed, T.; Amer, M.; Pan, J. (2008), 'Assessing risk and uncertainty inherent in Chinese highway projects using AHP,' International Journal of Project Management 26(4), doi:10.1016/j.ijproman.2007.05.012

Petr Rehacek and Blanka Bazsova (2018), Journal of Eastern Europe Research in Business and Economics, DOI:10.5171/2018.790198 